\title{
Extracting growth and inflation expectations from financial market data
}

\author{
Lauri Kajanoja, ${ }^{1}$ Bank of Finland
}

\section{Introduction}

Financial market prices are affected by market participants' expectations concerning future macroeconomic developments. However, expectations regarding real GDP growth, for example, cannot be directly observed in the price quotations for a financial market instrument. In order to gain information on such expectations, one needs to employ economic models in addition to financial market data.

Financial market participants' expectations concerning macroeconomic developments are obviously of great interest, not least to economic policymakers. These expectations, as they are reflected in financial market prices, are based on a huge amount of information. Naturally, they can be wrong, and each individual may disagree with them. Nonetheless, knowledge of market expectations does make it easier to understand current economic developments and to form one's own expectations concerning the future.

Various measures of market expectations concerning macroeconomic developments have been put forward. A widely used measure of inflation expectations is the so-called "break-even" inflation rate derived from the yield of an inflation-indexed bond. Break-even inflation rates are discussed for example by eg Sack (2000) and Scholtes (2002). Another market-based measure of inflation expectations can be derived from inflation-linked swaps, as reported by the ECB (2003). Measuring market expectations of real output growth seems to be a more formidable task. For measuring the market's perception of the output gap, Martin and Sawicki (2003) propose a method based on an inverted Taylor rule. Taking a broader view on measuring market expectations, one can also consider indicator models of growth and inflation that use financial market variables as inputs. Such models are widely used in short-term macroeconomic forecasting.

Stock prices and interest rates can be interpreted to yield information concerning market expectations of future output growth and inflation. High stock prices indicate fast expected growth of companies' earnings and dividends in the future. Long-term interest rates reflect expectations concerning both inflation and output in the long run; according to standard macroeconomic theory, the long-term interest rate is related to expected long-run output growth. However, stock prices and interest rates do not as such provide direct measures of real output growth or inflation expectations.

This paper presents a new framework for measuring market expectations concerning long-run inflation and real output growth. The method combines items of information contained in stock prices and interest rates. The framework can be directly applied to measuring expectations in real time. As inputs, it uses interest rates and dividend/price ratios for equity indices. In addition, equity index futures are utilised in gauging short-run expectations. The framework is based on economic theory. It builds on three elements: first, a dividend discount model of stock prices is used; second, it is assumed that expected long-run dividend growth is proportional to expected long-run GDP growth; and third, it is assumed that there is a stable linear relationship between the long-term real interest rate and the expected long-run real GDP growth.

The paper is organised as follows. Section 2 describes the methodology used. Section 3 presents the results; that is, the series of extracted growth and inflation expectations for the euro area and the United States. Section 4 concludes.

\footnotetext{
I am grateful to Jarmo Kontulainen, Hanna-Leena Männistö, Nicolas Rautureau, Tuomas Saarenheimo, Juha Tarkka, Nico Valckx, Jouko Vilmunen, and the participants in the Bank of Finland Research Department and Economics Department seminars and the BIS Central Bank Economists' Meeting for useful comments and suggestions.
} 


\section{Framework}

In this study, market expectations for long-run GDP growth and inflation are measured using the following data as inputs: interest rates, dividend/price ratios of equity indices, and equity index futures. This section presents the framework used to carry out the measurement. Section 2.1 describes how the dividend discount model is used in the framework. The method for deriving long-run expectations is further developed in Section 2.2. Section 2.3 then describes how near-term dividend growth expectations are measured using data on equity index futures. The near-term expectations are measured in order to improve the measurement of long-run expectations. Finally, Section 2.4 gives parameter values.

\section{$2.1 \quad$ Expected dividend growth}

Following the dividend discount model, we start from the assumption that stock prices equal expected discounted future dividends. The discount rate is the expected return on equity capital, which can be approximated by the risk-free interest rate plus an equity premium. Here, the latter is assumed to be constant. Therefore, the price of a stock at the end of period $t, P_{t}$, can be expressed as:

$P_{t}=\sum_{j=1}^{\infty} \frac{D_{t+j \mid t}}{\left(1+i_{j, t}+\omega\right)^{j}}=D_{t} \sum_{j=1}^{\infty} \frac{\left(1+n_{j, t+j \mid t}\right)^{j}}{\left(1+i_{j, t}+\omega\right)^{j}}$,

where $D_{t+j \mid t}$ denotes dividends paid during period $t+j$ as expected at the end of period $t, i_{j, t}$ denotes the risk-free interest rate in maturity $j$ at the end of period $t, \omega$ denotes the equity premium, and $n_{j, t+j \mid t}$ denotes the end of period $t$ expectation of the growth rate of nominal dividends from period $t$ till period $t+j$, in annual terms. In other words, the first subscript denotes the length of the time horizon for the variable, and the second subscript indicates when the value of the variable is realised. We take the length of a time period to be one year.

We do not assume that dividend growth is expected to be constant in the future. Instead, we decompose the expected dividend growth into short-run and long-run expectations. We use the following "term structure" assumption for the expected nominal dividend growth:

$$
1+n_{j, t+j \mid t}=\left(1+n_{1, t+1 \mid t}\right) \frac{1}{j}\left(1+n_{L R \mid t}\right) \frac{j-1}{j}
$$

where $n_{L R \mid t}$ denotes expected long-run nominal dividend growth. In addition, we use a similar approximation for the term structure of the discount rate:

$$
1+i_{j, t}+\omega=\left(1+i_{1, t}+\omega\right) \frac{1}{j}\left(1+i_{L R, t}+\omega\right) \frac{j-1}{j},
$$

where $i_{L R, t}$ denotes the long-term risk-free interest rate at the end of period $t$. The empirical definition of this variable will be given in Section 2.4 below.

Equations (1) to (3) imply, as an approximation, that:

$n_{L R \mid t}=i_{L R, t}+\omega-\frac{D_{t}}{P_{t}} \frac{1+i_{L R, t}}{1+i_{1, t}}\left(1+n_{1, t+1 \mid t}\right)$.

According to equation (4), market expectations concerning long-run nominal dividend growth can be inferred from current financial market prices, past dividends, and estimates of near-term dividend growth expectations and the equity premium.

\subsection{Measuring GDP growth and inflation expectations}

We assume that expected long-run dividend growth varies in proportion to expected long-run GDP growth. For an imaginary stock price index covering all firms in an economy, one could argue that these two should move one-to-one. For the stock price indices used here it is natural to assume that the expected long-run dividend growth rate varies more than the expected long-run GDP growth rate for the whole economy. Therefore, we assume that:

$n_{L R \mid t}-\pi_{L R \mid t}=\alpha+\beta g_{L R \mid t}$, 
where $\pi_{L R \mid t}$ denotes expected long-run inflation, $g_{L R \mid t}$ expected long-run real GDP growth, and $\alpha$ and $\beta$ positive constants. Equation (5) states the relationship between the expected real long-run dividend growth and the expected real long-run GDP growth. As discussed in Section 2.4 below, we will set $\beta$ close to 2 when the S\&P 500 Index for the United States is considered.

Let us next introduce an assumption concerning the relationship between expected long-run real GDP growth and the long-term real rate of interest. A standard consumption Euler equation from a representative consumer model combined with a market clearing condition, saying that consumption equals output, yields:

$r_{L R, t}+\omega_{Y} \approx \frac{1}{\delta} \frac{u^{\prime}\left[Y_{t}\right]}{u^{\prime}\left[\left(1+g_{L R \mid t}\right) Y^{t}\right]}-1$,

where $\delta$ denotes the discount factor, $u^{\prime}$ is the first derivative of the period utility function, and $Y_{t}$ denotes period $t$ real consumption, which equals real output. $\omega_{Y}$ denotes a risk premium. It is not assumed to be equal to the $\omega$ of equation (1), since $\beta$ is allowed to differ from 1 in equation (5). The long-term real interest rate is denoted by $r_{L R, t}$, and defined as:

$r_{L R, t}=i_{L R, t}-\pi_{L R \mid t}$.

Equation (6) can be linearised to yield, as an approximation:

$r_{L R, t}=\rho+\lambda g_{L R \mid t}$.

This linearisation holds for positive constants $\rho$ and $\lambda$, the latter of which represents the inverse of the elasticity of intertemporal substitution.

Equations (4), (5), (7) and (8) can be combined to yield the following system of equations:

$$
\begin{aligned}
& g_{L R \mid t}=\frac{\rho+\gamma}{\beta-\lambda}-\frac{1}{\beta-\lambda} \frac{D_{t}}{P_{t}} \frac{1+i_{L R, t}}{1+i_{1, t}}\left(1+n_{1, t+1 \mid t}\right), \\
& \pi_{L R \mid t}=i_{L R, t}-\rho-\frac{\lambda(\rho+\gamma)}{\beta-\lambda}+\frac{\lambda}{\beta-\lambda} \frac{D_{t}}{P_{t}} \frac{1+i_{L R, t}}{1+i_{1, t}}\left(1+n_{1, t+1 \mid t}\right),
\end{aligned}
$$

where $\gamma$ denotes a constant defined as $\gamma \equiv \omega-\alpha$. Equations (9) and (10) express the expected long-run real GDP growth and inflation in terms of (1) current observable variables: $D_{t}, P_{t}, i_{L R, t}, i_{j, t}$; (2) parameters: $\lambda, \rho, \gamma$; and (3) expected one-year-ahead growth in nominal dividends $n_{1, t+1 \mid t}$.

In the next section we deal with the near-term expectations $n_{1, t+1 \mid t}$. After that, we set values for the parameters $\lambda, \rho, \gamma$ and $\beta$. Then we are ready to use equations (9) and (10) empirically to extract market expectations for the euro area and for the United States.

\subsection{Measuring short-run dividend growth expectations}

The framework presented in this paper is constructed in order to extract market expectations concerning long-run developments. Sometimes when the dividend discount model is utilised in extracting market expectations, the expected dividend growth rate is assumed to be constant in the future. Expectations derived in such a way reflect, to a large extent, short-run expectations. This is because short-run expectations seem to vary more than long-run expectations, and because they have a larger weight in the dividend discount model due to the discounting. Therefore, we deal with long- and short-run expectations separately, as shown in Section 2.1.

Regarding expectations concerning near-term stock returns, one way to proceed would be to use stock analysts' bottom-up predictions. However, in the current context this approach would have an obvious drawback: the predictions are not available on a real-time basis. In addition, such predictions are known to have a significant upward bias. The approach chosen here is therefore to use the information contained in equity index futures quotations.

\subsubsection{Expectations and equity index futures: the idea}

Short-run dividend growth expectations can be extracted from financial market data using the principle of equation (1) and the prices of equity index futures, financial derivatives whose underlying assets are 
equity indices. The value of an equity index future reflects the market expectations concerning the value of the index in the future as well as expectations regarding dividends paid out before the future matures.

Let us start by stating that:

$$
\frac{D_{t+1 \mid t}+F_{t+1, t}}{P_{t}}=1+i_{1, t}+\omega_{D 1} \text {, }
$$

where $F_{t+1, t}$ denotes the end of period $t$ market delivery price for an equity index future concerning a contract maturing at the end of period $t+1,{ }^{2}$ and $\omega_{D 1}$ denotes a risk premium.

The left-hand side of equation (11) is the expected gross return from an investment strategy where equities underlying the index are bought in period $t$ and sold in period $t+1$ for a price set in a futures contract made in period $t$. In practice this means holding the stocks for one period and hedging against stock price movements by selling short equity index futures in period $t$. The expected return from this strategy must equal the right-hand side of the equation, that is, 1 plus the risk-free interest rate plus the risk premium $\omega_{D 1}$ related to the uncertainty concerning $D_{t+1}$ as of time $t$. This risk premium is related to but not equal to the $\omega$ of equation (1). It is likely to be very small and can safely be ignored in the following calculations.

Equation (11) shows that the difference between the current equity index value $P_{t}$ and the futures contract price $F_{t+1, t}$ reflects two things: expected next period dividends and the discount rate. The larger the expected next period dividends, the smaller the futures contract price, other things being equal. This reflects the fact that next period dividends will be paid out before the futures contract is settled, and paying out dividends decreases the value of a firm, ceteris paribus. Equation (11) naturally holds only for equity indices not adjusted for cash dividends, that is, those that are not so-called total return indices. Most widely used equity indices, including the ones used in this study, are not total return indices.

Using the notation $1+n_{1, t+1 \mid t}=D_{t+1} / D_{t}$ and ignoring the risk premium, equation (11) can be rewritten as:

$$
n_{1, t+1 \mid t}=\frac{P_{t}}{D_{t}}\left(1+i_{1, t}-\frac{F_{t+1, t}}{P_{t}}\right)-1
$$

Equation (12) shows that one can infer the expected one-period nominal dividend growth $n_{1, t+1 \mid t}$ from the values of $F_{t+1, t}, P_{t}, D_{t}$ and $i_{1, t}$, all of which are observable at the end of period $t$.

\subsubsection{Expectations and equity index futures: a detailed account}

In practice, equity index futures exist only for certain maturity dates. Rather than using equation (12) empirically, it is simpler to use data on equity index futures with different maturities. In this section, we use daily frequency in time notations. In the empirical analysis we will use data from money markets which have adopted the so-called actual/360 method for interest rate calculations, also known as the $365 / 360$ method. Therefore, using daily frequency and annualised interest rates, equation (11) should be written as:

$$
P_{t}=\frac{F_{T, t}+D_{(t, T) t}}{1+\frac{T-t}{360} \cdot i_{T-t, t}},
$$

where $T$ denotes the maturity date of the future, and $D_{(t, T) \mid t}$ denotes the day $t$ expectation of the day $T$ value of dividends that will be paid during the days $t+1, t+2, \ldots, T$. The maturity of the relevant interest rate is now $T-t$ days. When equation (13) is written for two different future dates, $T=T_{1}$ and $T=T_{2}$, combining these two equations by eliminating $P_{t}$ yields:

2 Here, we use an index future for which the delivery price is quoted in terms of the value of the index itself. 
$\frac{D_{\left(t, T_{2}\right) t}}{1+\frac{T_{2}-t}{360} \cdot i_{T_{2}-t, t}}-\frac{D_{\left(t, T_{1}\right) t}}{1+\frac{T_{1}-t}{360} \cdot i_{T_{1}-t, t}}=\frac{F_{T_{1}, t}}{1+\frac{T_{1}-t}{360} \cdot i_{T_{1}-t, t}}-\frac{F_{T_{2}, t}}{1+\frac{T_{2}-t}{360} \cdot i_{T_{2}-t, t}}$.

Equation (14) can be rewritten to express the expected divident stream as:

$D_{\left(T_{1}, T_{2}\right) \mid t}=\frac{1+\frac{T_{2}-t}{360} \cdot i_{T_{2}-t, t}}{1+\frac{T_{1}-t}{360} \cdot i_{T_{1}-t, t}} F_{T_{1}, t}-F_{T_{2}, t}$,

where $D_{\left(T_{1}, T_{2}\right) \mid t}$ denotes the day $t$ expectation of the day $T_{2}$ value of the dividends that will be paid out during the days $T_{1}+1, T_{1}+2, \ldots, T_{2}$.

We approximate the near-term annual expected dividend growth rate $n_{1, t+1 \mid t}$ by:

$n_{1, t+1 \mid t}=\frac{D_{\left(T_{1}, T_{2}\right) t}}{D_{\left(T_{1}-365, T_{2}-365\right)}}-1$

where the dividends in the denominator are already observed on day $t$. Equation (16) shows how the near-term dividend growth expectations can be extracted from the prices of equity index futures and money market interest rates. ${ }^{3}$ In practice, the equity index futures used mature at the end of each quarter. Therefore, the numerator of equation (16) refers to dividends paid out during some quarters in the future, and the denominator refers to the dividends that were paid out during the same quarters one year earlier.

Based on equation (16), Figures 1 and 2 show the expected near-term nominal dividend growth rates for two equity indices. The Standard \& Poor's 500 Index represents US stocks, and the Dow Jones EURO STOXX 50 represents euro area stocks. The series depicted in Figures 1 and 2 result from using equity index futures such that the growth rate given by the right-hand side of equation (16) refers to the one that is expected to prevail about half a year into the future.

To be exact, for the S\&P 500 Index, we use prices for the futures contract that is the next one to mature and for the fourth one to mature. This means that we are measuring market expectations concerning the dividends that will be paid out during the next three full calendar quarters. For the DJ EURO STOXX 50 index, we deal with dividends to be paid out during the next two full calendar quarters. In the case of the DJ EURO STOXX 50 the contracts that mature further in the future do not exist, and in the case of the S\&P 500 they have a shorter history. As the empirical counterparts for the interest rates that appear in equation (15) we use money market interest rates, linearly interpolated for different maturities when necessary.

The $n_{1, t+1 \mid t}$ series shown in Figures 1 and 2 are not given directly by equation (16). Two modifications are made to the series. First, to smooth out what seems to be noise, we use moving averages: the past 90 days moving average for the S\&P 500 and the past 30 days for the DJ EURO STOXX 50. In addition, there seem to be some premia affecting the futures prices or some other institutional factors that remain unaccounted for, so that the variances of the series given by equation (16) are implausibly large. Therefore, we regress realised ex post dividend growth series on the series given by equation (16) and use the fitted values from those linear regressions as the $n_{1, t+1 \mid t}$ series shown in Figures 1 and $2 .^{4}$

3 For leap years the figure 365 is replaced by 366 in the subscript of the denominator.

$4 \quad$ All available data are used in the estimations. For the S\&P 500 the estimation period extends from the third quarter of 1991 to the third quarter of 2002, and for the DJ EURO STOXX 50 from the first quarter of 1991 to the third quarter of 2002. The data for the explanatory variable are mid-quarter values. We use ordinary least squares. The slope estimates are greater than zero, as expected, and in the case of the S\&P 500 the estimate is statistically significant. 


\section{4}

Parameter values

Now we are almost ready to use equations (9) and (10) in extracting expectations. What remains to be done is to set the values for the parameters $\lambda, \rho, \gamma$ and $\beta$, using published macroeconomic forecasts. In the case of $\lambda$, we also make use of restrictions stemming from economic theory. The daily financial market data used here are provided by Bloomberg.

For the United States, we start by setting $\beta$ so that it equates the standard deviations of the two sides of equation (5). We use the right-hand side of equation (4) as the empirical counterpart of $n_{L R \mid t}$. The series for the long-term interest rate $i_{L R, t}$ is calculated by solving equation (3) for it with $j=10, i_{10, t}$ being the 10-year government bond yield and $i_{1, t}$ the 12-month money market interest rate. ${ }^{5}$ Here, for $\pi_{L R \mid t}$ and $g_{L R \mid t}$ we use the inflation and real GDP growth forecasts made by the Congressional Budget Office (CBO). We use the forecasts for three to five years ahead, so as not to include the forecasts for the first two years. The standard deviations of the two sides of equation (5) are then calculated for the period 1991-2002, as the data on equity index futures start in 1991. For $n_{L R \mid t}$ we use end-of-year values, since the CBO publishes its forecasts close to the end of the year. The resulting $\beta$ equals 1.98 .

Once the value of $\beta$ is set, we obtain the rest of the parameter values for the United States by estimating equations (9) and (10) as a system with parameter restrictions. As left-hand side variables, we use CBO long-run forecasts. As such, the statistical model of the forecasts is of no interest to us. The purpose of the estimation exercise, loosely speaking, is to set the values for the parameters so that equations (9) and (10) produce expectation series with averages and variances in line with the published forecasts that are used as benchmarks here. As the empirical counterparts of $\pi_{L R \mid t}$ and $g_{L R \mid t}$ we again use CBO long-run forecasts. The data set extends from 1991 to 2002 in annual frequency, and we again use end-of-year values for the financial market variables.

We estimate the system using the method of maximum likelihood, with the assumption that the error terms are normally distributed, assuming the parameter restrictions given below. The estimation is performed numerically. The parameter restrictions include having the same values for $\lambda, \rho$ and $\gamma$ in both equations. In addition, we restrict the value of $\lambda$ to greater than or equal to 0.5 . This restriction for the elasticity of intertemporal substitution is based on macroeconomic literature. Unrestricted, the estimate of $\lambda$ would be lower and thus inconsistent with the theoretical starting point of the framework. The restriction for $\lambda$ turns out to be binding, and the estimate of $\lambda$ is thus 0.5 . The estimate of $\rho$ equals 0.022 , and the estimate of $\gamma$ is 0.0375 . The fitted values of the equations are depicted in Figures 3 and 4.

For the euro area, data on futures prices have been available only since the beginning of 1999. The value of $\beta$ is set as for the United States, now based on the forecasts made by Consensus Economics Inc. We use the forecasts for three to seven years ahead, so as not to include the forecasts for the first two years. The forecasts for euro area averages are approximated by weighted averages of the five largest euro area economies. The inflation forecasts are calculated from the real and nominal GDP growth forecasts. The long-run consensus forecasts are published in August each year. Therefore, we use end-of-July values for $n_{L R \mid t}$. The resulting $\beta$ parameter for the euro area is 4.98 .

With the data series for the euro area being very short, we do not estimate equations (9) and (10) for the euro area. Rather, we set $\lambda$ at 0.5 , following the United States value. The values for $\rho$ and $\gamma$ are then calculated using equations (9) and (10), setting the variables in these two equations at their average values for 1999-2002. For $g_{L R \mid t}$ and $\pi_{L R \mid t}$ we again use consensus forecasts. The resulting values for $\rho$ and $\gamma$ are, respectively, 0.0214 and 0.103 .

\section{Results: long-run expectations}

The long-run expectations given by the framework are presented in Figures 5 to 13 . That is, these figures show the $g_{L R \mid t}$ and $\pi_{L R \mid t}$ series given by equations (9) and (10), using the parameter values

5 Here, we make the approximation that $\omega=0$. 
described in the previous section. The series are derived from daily data on equity indices, dividends, interest rate and equity index futures. The data are provided by Bloomberg. The last data point in these figures is 7 November 2003.

Figures 5 and 7 present the expected long-run inflation and GDP growth rates for the United States. According to the results, the markets' long-run inflation expectations have been on a declining trend since 1991. This is not surprising, since in the 1990s the inflation rate slowed considerably in the United States, as seen in Figure 7. The credibility of US monetary policy regarding price stability seems to have increased since the early 1990s. Figure 8 shows that inflation expectations evolve to some extent similarly to long-term inflation forecasts and to a break-even inflation rate derived from an inflation-indexed bond. Recently, however, the level of inflation expectations has been very low. In terms of the framework, this is mainly due to the very low long-term interest rates.

While inflation expectations were lowered in the 1990s, the expected long-run GDP growth rate increased over the same period, according to the results. This is in line with the accelerated productivity growth seen in the United States, and with upward revisions in growth forecasts, such as those presented in Figure 6. The strong upward movement in expected real GDP growth implied by the framework largely reflects the increases in stock prices seen in the late 1990s. Similarly, the recent fall in stock prices implies a fall in the growth expectation series. The turning point towards lower growth expectations is earlier than the corresponding turning point in the forecasts shown in Figure 6.

The results for the euro area are presented in Figures 9 to 12. These results cover only the period since 1999, because the data for the equity index futures are unavailable before that. Even during this period, there are some gaps in the data, which can be seen in the figures. Similarly to US expectations, euro area growth and inflation expectations have diminished somewhat since the year 2000, and the turn for the worse in the growth expectation series takes place earlier than in the published growth forecasts (Figure 10).

In order to consider longer time series for the euro area, we investigate a version of the framework that differs from the one presented in the preceding sections. Figure 13 depicts growth and inflation expectations derived under the assumption that growth and inflation rates are expected to be constant in the future. That is, the series shown in Figure 13 are derived making the assumptions that $n_{1, t+1 \mid t}=n_{L R \mid t}$ in equation (2), and $i_{1, t}=i_{L R, t}$ in equation (3). Since the near-term expectations are not treated explicitly in this version of the framework, data on equity index futures are not required. Therefore, the results can be shown for a longer time span than in the case presented in Figures 9 to 12. According to Figure 13, changes in growth and inflation expectations in the euro area since the early 1990s have been to some extent similar to those in the United States. However, changes in growth expectations have been somewhat smaller in the euro area, and the drop in inflation expectations has been greater.

\section{Conclusions}

This study presents a framework for measuring financial markets' expectations concerning long-run real GDP growth and inflation. The framework is based on economic theory, and uses as inputs data on equity indices, dividends, interest rates and equity index futures prices. Using the framework, market expectations can be measured in real time.

Obviously, it is impossible to determine the "true" market expectations. First, there is no unique set of market expectations, in the sense that the expectations of individual market participants differ. What is being measured in all attempts to gauge market expectations is a sort of noisy weighted average of the individual market participants' expectations. Second, that weighted average can only be observed with limited accuracy: we do not know which of the different measures presented in Figures 6, 8, 10 and 12 are closest to the "truth".

To some extent, the measures of market expectations produced by the framework presented here are similar to some other measures and published forecasts. However, in several instances this is not the case. For example, our measures of US growth expectations differ from other measures during the early part of the 1990s and again the period 2002-03, as shown in Figure 6. During the latter period the same is true for US inflation expectations, as shown in Figure 8. 
Regarding recent developments, one can speculate whether the results of this framework imply that the growth forecasts shown in Figure 6 will be revised down in the near future, following the downturn in the expectation series. After all, the level of stock prices compared with past dividends has settled at a level considerably lower than that which prevailed in the late 1990s. Generally, the measures of growth expectations presented here have been strongly influenced by changes in stock prices.

The recent low inflation expectations shown in Figure 8, in turn, reflect low long-term nominal interest rates. This suggests that the fall in interest rates during recent years has been large even relative to the fall in stock prices. This interpretation is based on the fact that our measure of inflation expectations is affected by both nominal interest rates and stock prices as shown in equation (10): stock prices have not fallen enough to counteract the effect of the fall in interest rates. If this result is taken seriously, then one of the following must be true: (1) the market currently expects long-term inflation to be lower than the published forecasts indicate; (2) stock prices are still too high compared with expectations concerning the macroeconomy; (3) inflation expectations are not, for some reason, fully priced into long-term interest rates.

The framework presented here is new and experimental. In addition to the discussion above, one interpretation of the differences between the measures of expectations is that the framework is flawed in one way or another. Naturally, one can identify some potential problems with the approach. One is that equation (5), presenting the relationship between the expected GDP and dividend growth rates, may not hold empirically. It is difficult to assess how severely this equation may be misspecified.

In addition, it is possible that some other parameters of the model framework are not stable. For example, one might think that the assumption of a constant equity premium does not hold, even though this assumption is often made in applied work. In this respect, one way to try to improve the framework presented here would be to consider modelling the variation in the equity premium. Further, it is possible that the relationship between the long-term real interest rate and expected long-run real GDP growth is not stable. Finally, international linkages in the bond and equity markets have not been taken into account in the framework. For example, the real interest rates in the United States and in the euro area undoubtedly also reflect developments in other parts of the world. Dealing explicitly with such international linkages would be another way to possibly improve this framework in future work.

While the framework presented here provides measures of market expectations, it does not attempt to determine whether the expectations later turn out to be correct or not. Therefore, we do not need to take a stand when it comes to the question of whether there are bubbles in financial markets. We simply interpret market prices to reflect market expectations. However, if bubbles exist, they can be problematic for the method we use. This is because we assume that similar growth and inflation expectations are reflected in both stock prices and bond prices. When talking about bubbles, macroeconomists often have stock prices in mind more than interest rates. After all, there is strong evidence that the value of the S\&P 500 Index, for example, has tended to vary too much with respect to the subsequent changes in dividends. Large swings in the dividend/price ratio have been followed by large movements in stock prices and not in dividends, as documented by Campbell and Shiller (2001), among others. In addition to stock prices, however, it is naturally possible to argue that there are bubbles in bond prices as well. For example, some economists explained the very low level of long-term interest rates in mid-2003 in terms of a bond market bubble. 
Figure 1

S\&P 500: short-run growth in nominal dividends

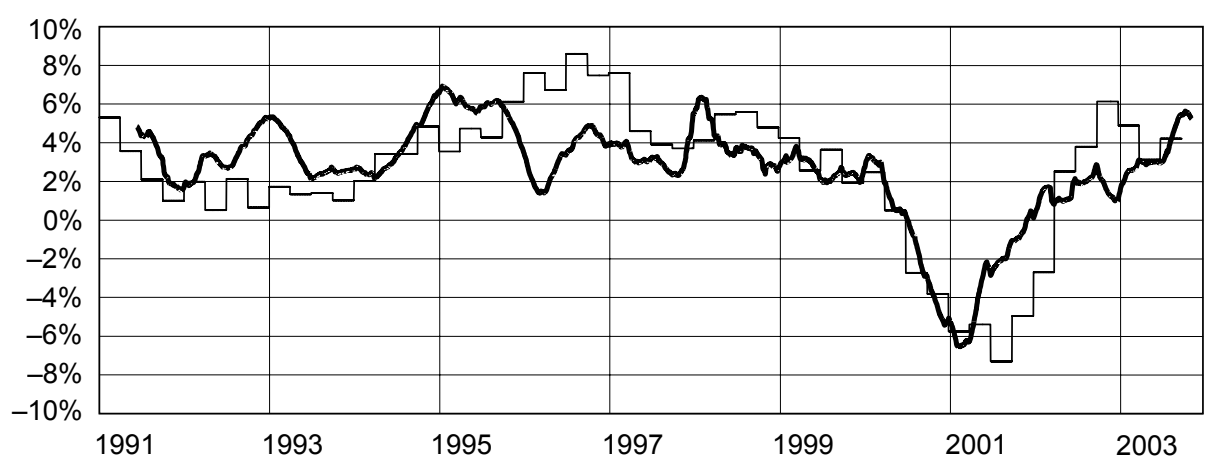

- Expected nominal dividend growth, from a year earlier, approximately six months ahead - Nominal dividend growth, from a year earlier

Figure 2

\section{DJ EURO STOXX 50: short-run growth in nominal dividends}

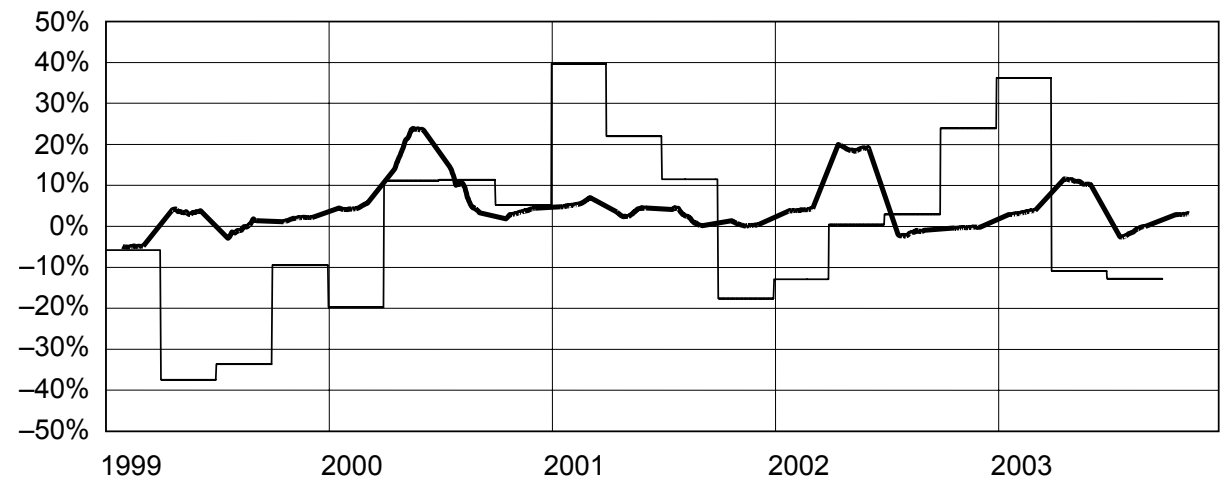

Expected nominal dividend growth, from a year earlier, approximately $41 / 2$ months ahead Nominal dividend growth, from a year earlier

Figure 3

United States: long-run growth forecast (СВO) and fit

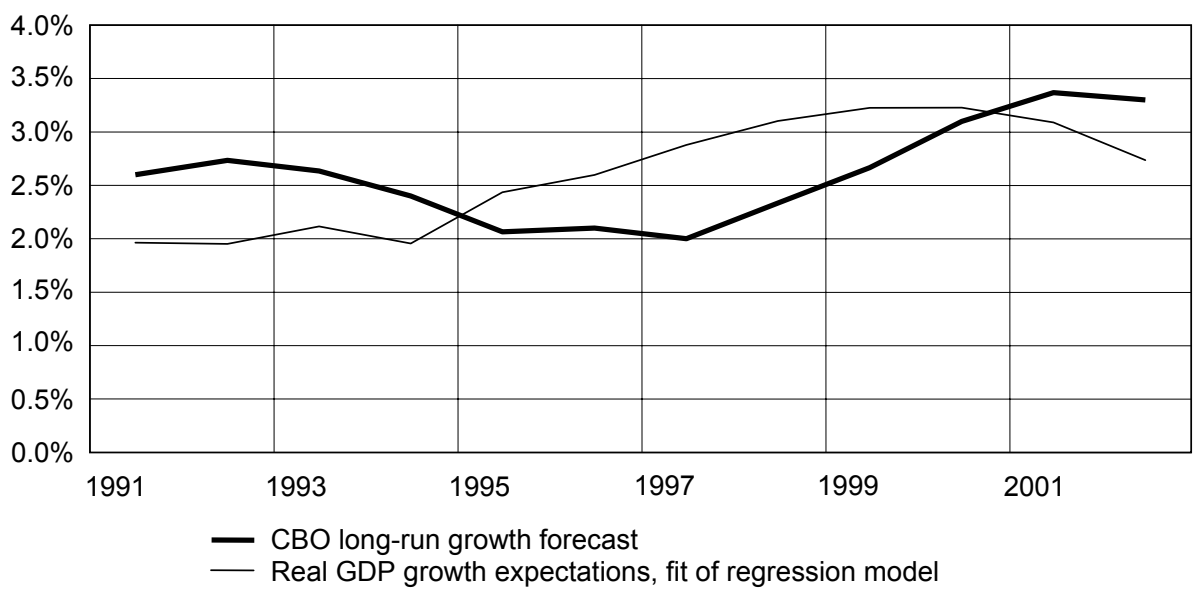


Figure 4

United States: long-run inflation forecast (СВО) and fit

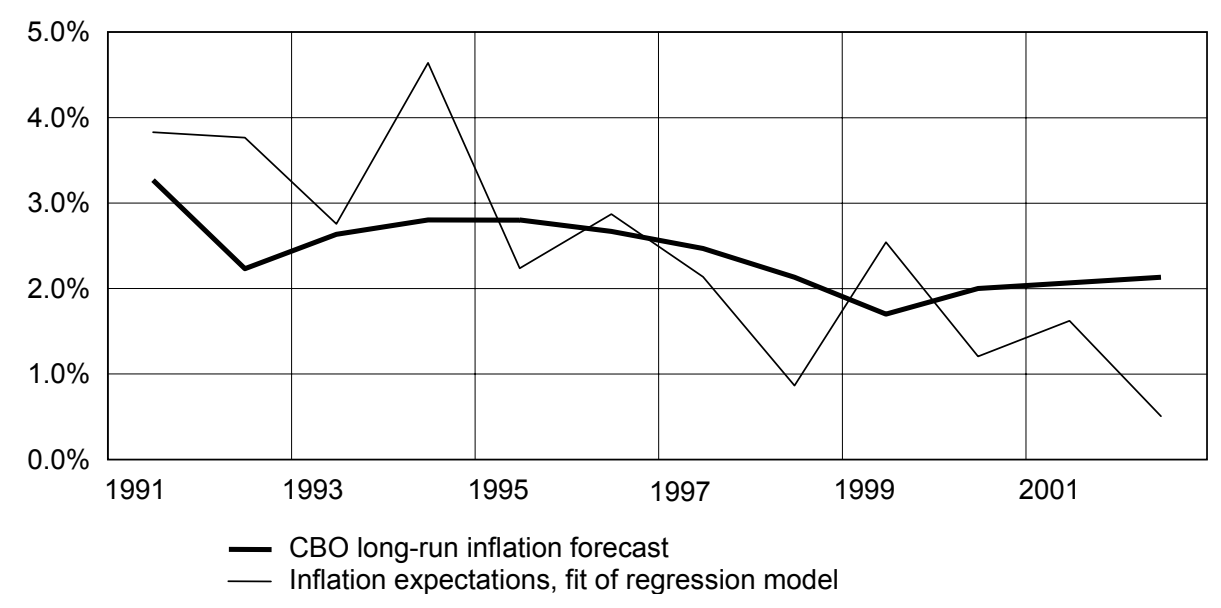

Figure 5

United States: expected long-run growth

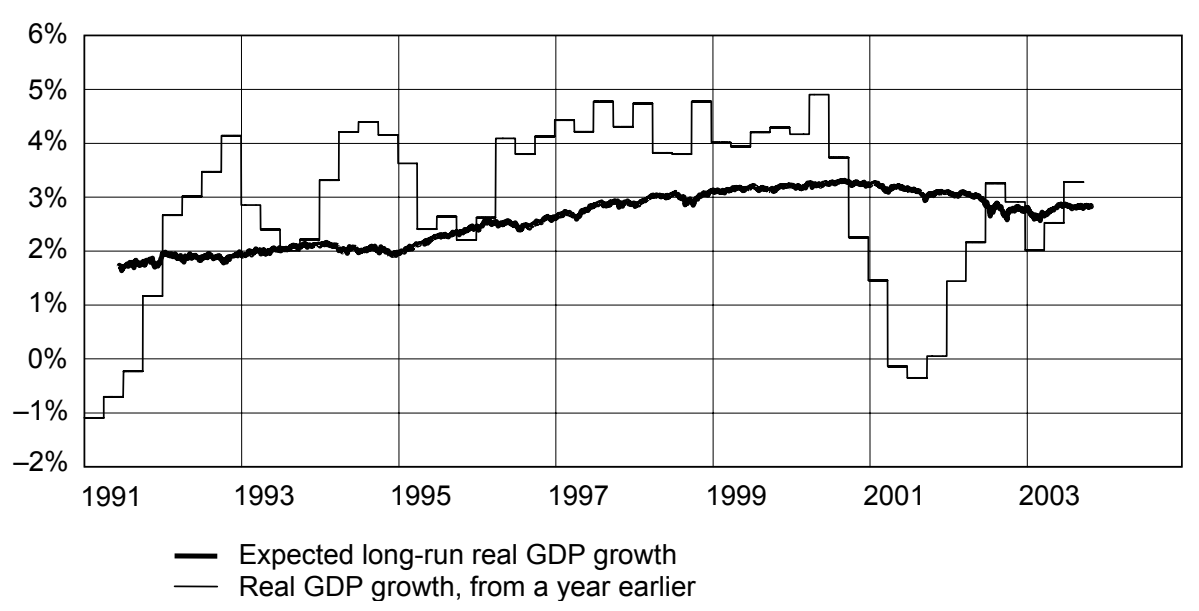

Figure 6

United States: expected long-run growth

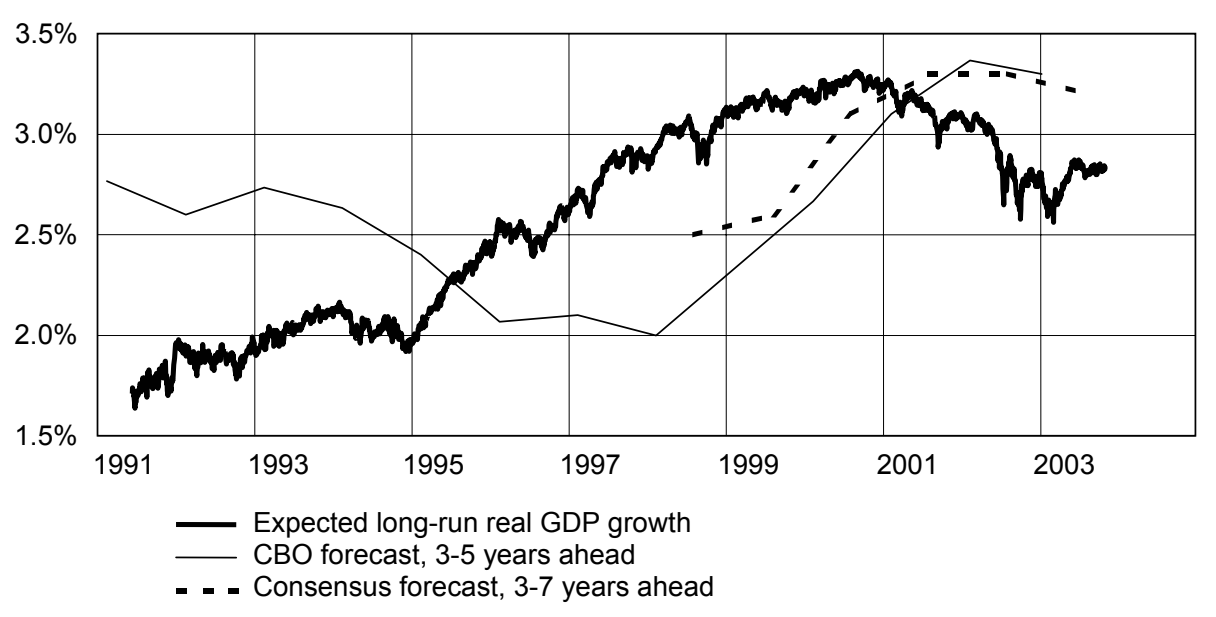


Figure 7

United States: expected long-run inflation

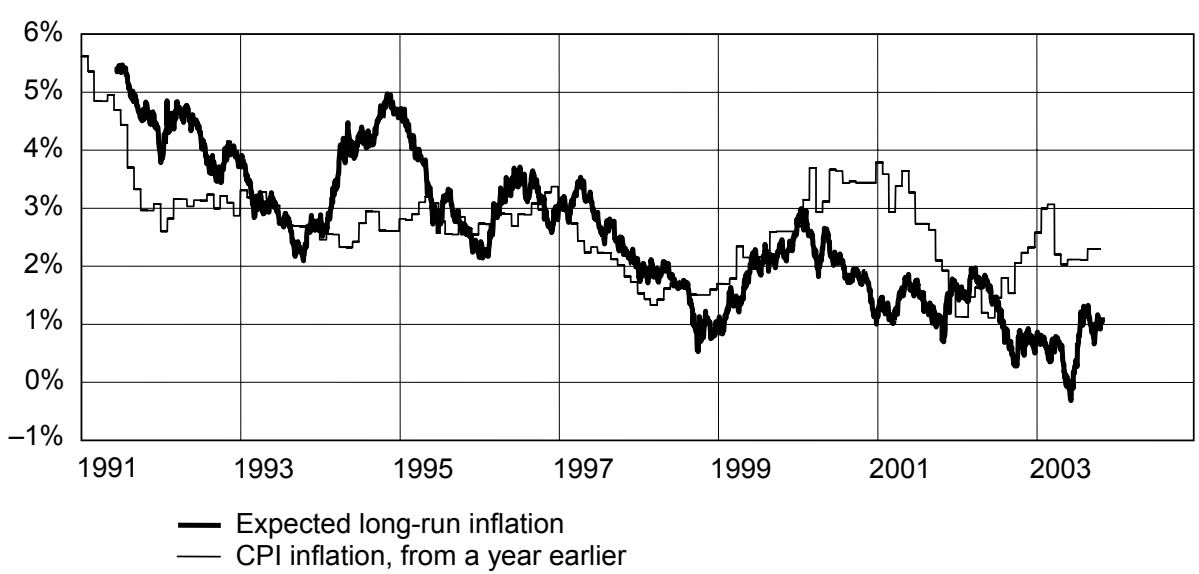

Figure 8

United States: expected long-run inflation

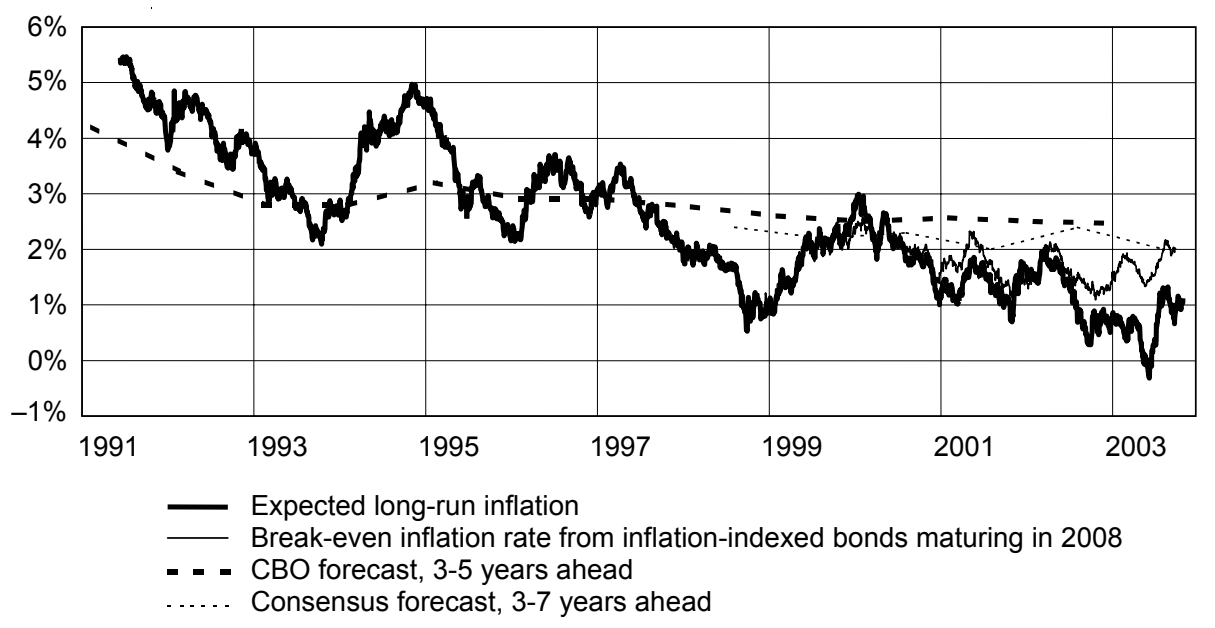

Figure 9

Euro area: expected long-run growth

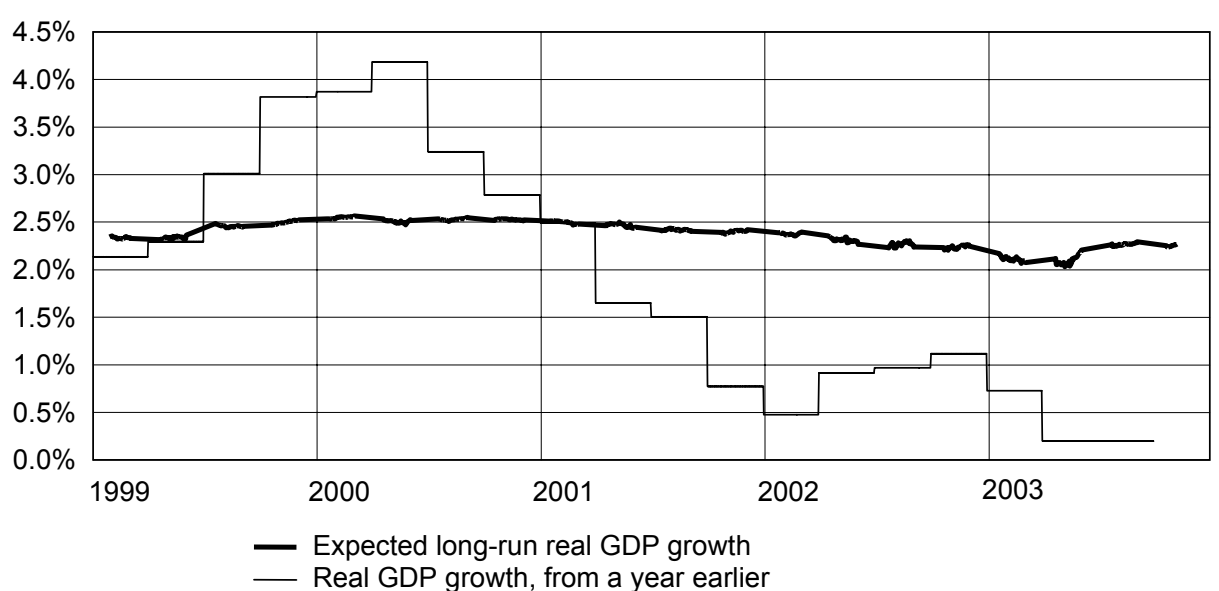


Figure 10

Euro area: expected long-run growth

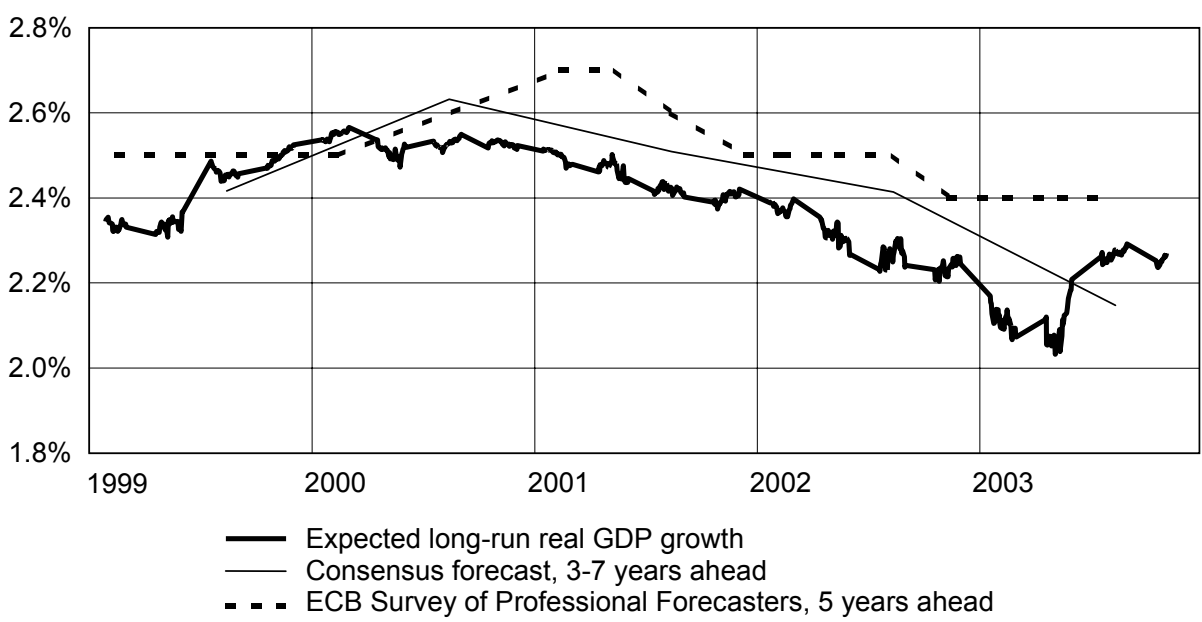

Figure 11

Euro area: expected long-run inflation

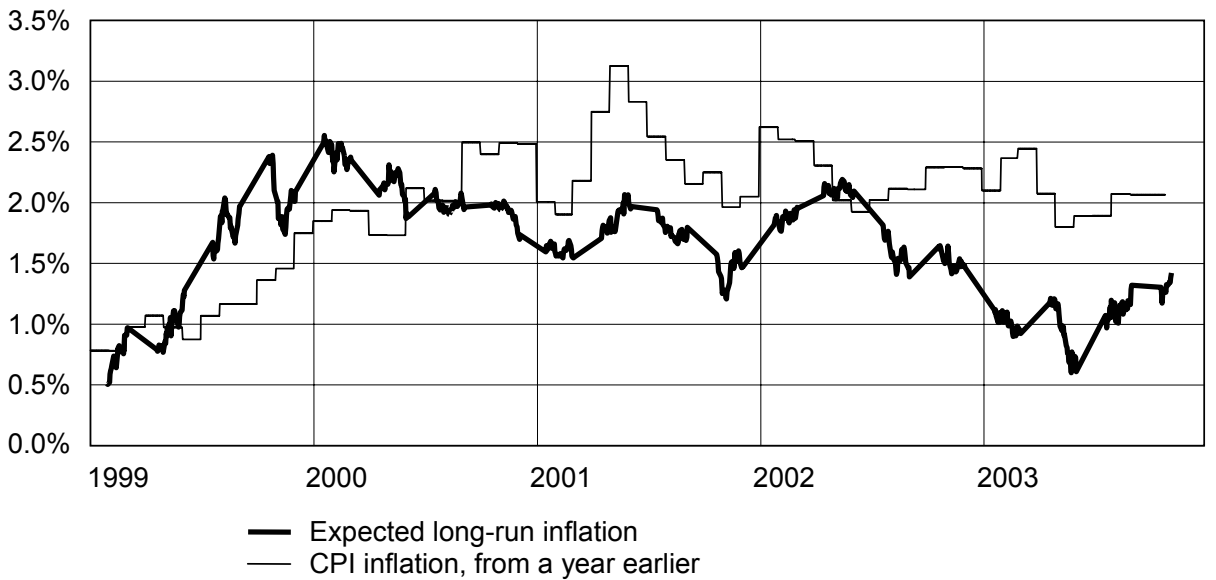

Figure 12

Euro area: expected long-run inflation

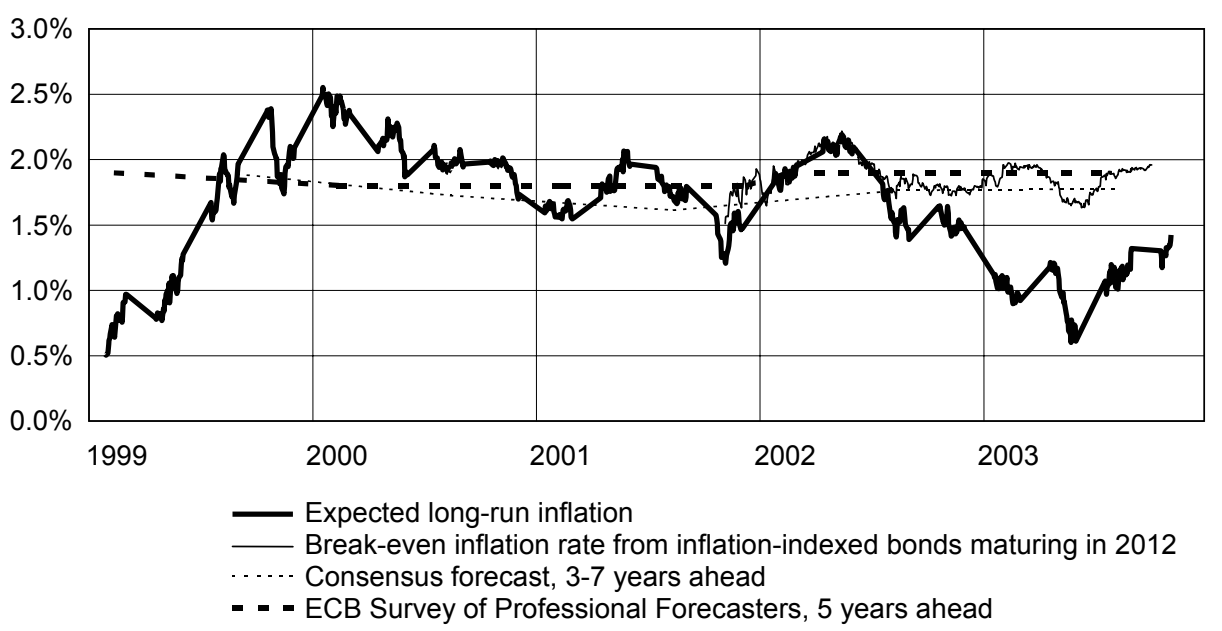


Figure 13

Euro area: long-run expectations, assuming constant expected rates of growth and inflation

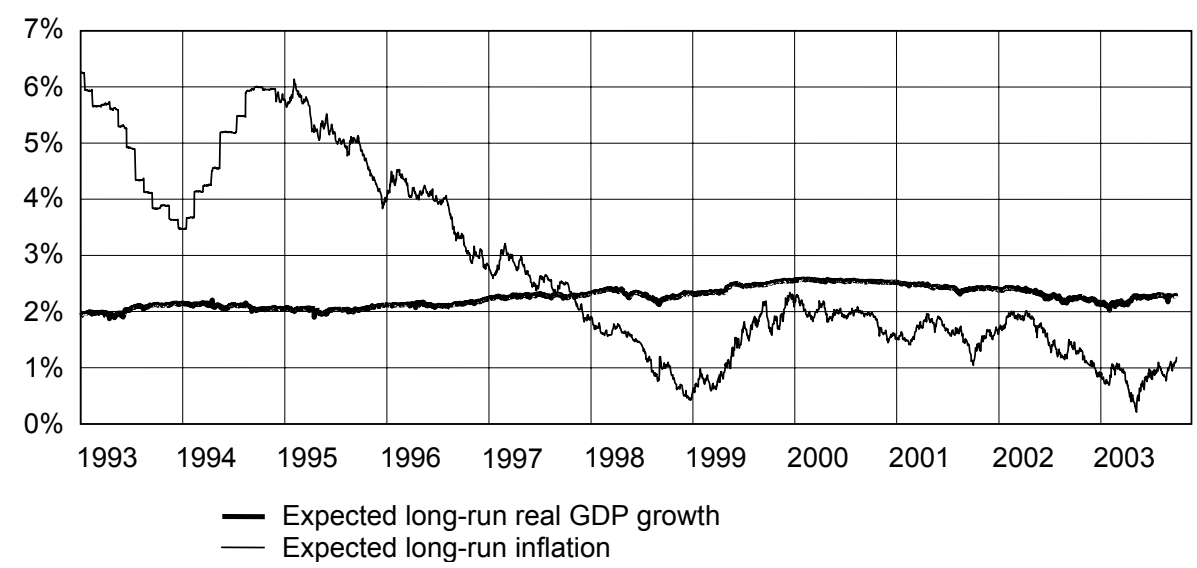

\section{References}

Campbell, John Y, Robert Shiller (2001): "Valuation ratios and the long-run stock market outlook: an update", NBER Working Paper, no 8221.

European Central Bank (2003): "Deriving euro area inflation expectations from inflation-linked swaps", ECB Monthly Bulletin, September, pp 31-2.

Martin, Ben and Michael Sawicki (2003): "Market-based estimates of expected future UK output growth", Bank of England Quarterly Bulletin, Spring, pp 20-6.

Sack, Brian (2000): "Deriving inflation expectations from nominal and inflation-linked treasury yields", Journal of Fixed Income, vol 10, pp 6-17.

Scholtes, Cedric (2002): "On market-based measures of inflation expectations", Bank of England Quarterly Bulletin, Spring, pp 67-77. 